\title{
DESARROLLO LOCAL: \\ TEORÍA, CRÍTICA Y CUESTIONAMIENTOS
}

\author{
José Sánchez Parga*
}

El actual ocaso de las sociedades rurales o campesinas coincide con la culminación del proceso urbanizador, donde se expresa tanto el moderno modelo de acumulación y concentración de riqueza en la sociedad postsocietal, como el fenómeno de la globalización de la "sociedad-enredes", "en flujos", "sociedad-demercado". Se trata por consiguiente de explicar a qué responde esta fase terminal de urbanización del mundo ( $y$ su desaruralización) y la categoría teórico-práctica de "lo local" en el contexto de la globalización. Dicho fenómeno no es ajeno a una modernizadora "descentralización del Estado" tendiente a desarrollar los gobiernos regionales y locales con una creciente transferencia de poderes politicos, competencias administrativas y recursos. Pero este fenóme-
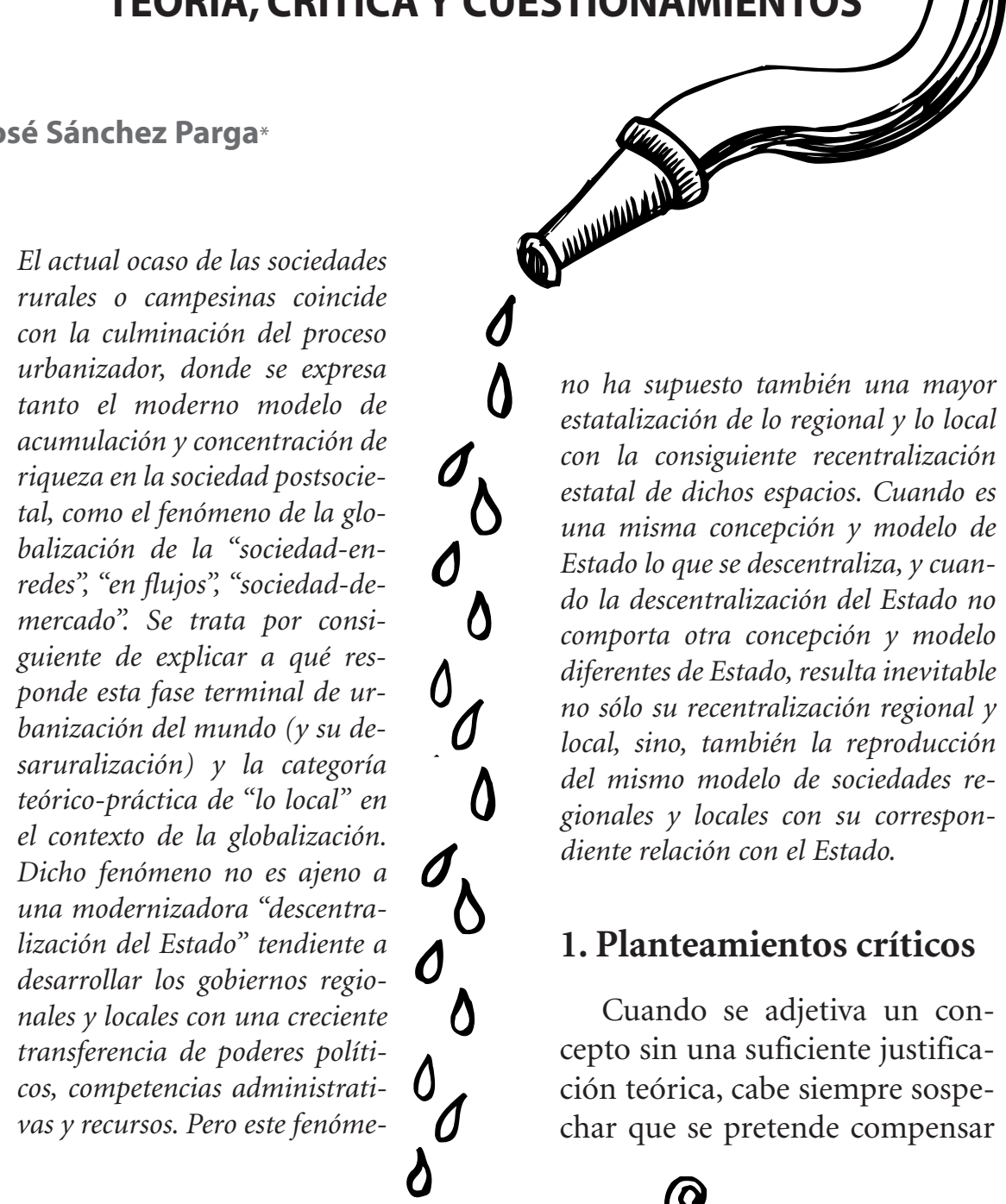

\section{Planteamientos críticos}

Cuando se adjetiva un concepto sin una suficiente justificación teórica, cabe siempre sospechar que se pretende compensar

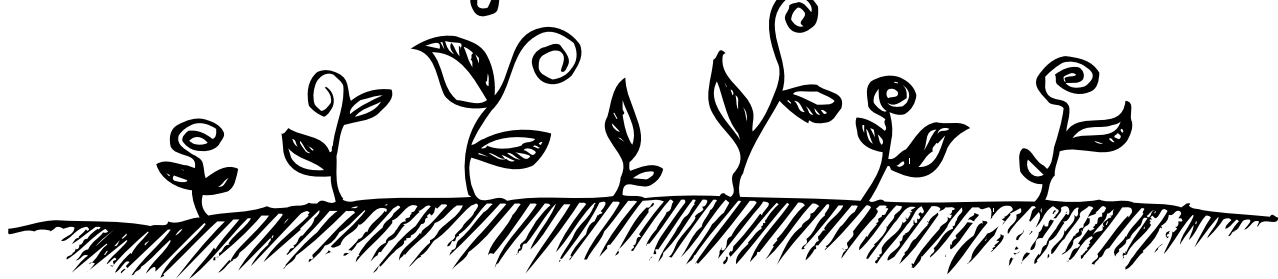

* Docente de la Universidad Politécnica Salesiana, investigador del Centro Andino (CAAP), Quito. 
con un epíteto la pérdida de substantividad de la realidad significada. Esto parece haber ocurrido con el " $d e$ sarrollo", desde que se comenzó a pensar "el fin del desarrollo", y esto mismo explicaría que hoy se hable tanto de "desarrollo humano", "desarrollo sostenible", "desarrollo local", etc ${ }^{1}$. Ahora bien, cuando una idea se pone de moda, como ha sido el caso del "desarrollo local", tiende tenazmente a resistir los análisis teóricos y críticos, tanto de sus presupuestos ideológicos como de las fuerzas e intereses que lo han producido y difundido. Sin embargo, tales cuestionamientos no dejan de ser necesarios, para evitar que dichas nociones se presten a prácticas ideológicas con frecuencia tan ineficaces como en ocasiones contraproducentes.

En el caso del desarrollo "local" la paradoja se muestra muy obvia: cuanto más parece la globalización despojar a las instancias territoriales de su posibilidad de controlar los reales procesos económicos y políticos, tanto más la idea de localidad territorial parece concentrar las virtualidades de un desarrollo, que más bien resulta cada vez más incierto, cuestionable o descartado a nivel nacional, concentrando en los espacios más inmediatos y concretos todas las expectativas y demandas colectivas de un posible desarrollo: "el desamparo de las políticas frente a la desterritorialización de la economía mundializada... coexiste con la fiebre del anclaje territorial, que parece deber sostener de nuevo tantas políticas públicas"2.

Los debilitamientos económico-políticos e institucionales, debidos a los procesos de globalización y procurados por las políticas neoliberales y de "ajuste estructural", todo ello conducido por los organismos financieros internacionales (FMI, Banco Mundial), han readecuado los poderes y las administraciones en beneficio de las colectividades públicas infranacionales; permitiendo así, una mejor articulación y dependencia de lo local con lo internacional.

En contra de las habituales simplificaciones y de los presupuestos muy diferentes de ambos fenómenos, "descentralización y desarrollo local no son directamente asimilables en razón de la diversidad de realidades empíricas abordadas y de la

1 Entre la abundante literatura sobre "el fin del desarrollo" puede consultarse Fernando Mires, El Discurso de la Miseria o Crisis de las Ciencias Sociales en América Latina, Nueva Sociedad, Caracas, 1993.

2 Martin Vanier, "Quel pouvoir économique pour les pouvoirs territoriaux?", en La Pensée, n. 314, 1998: 91. 
pluralidad de construcciones analíticas que intentan apuntar"3. De otro lado, el desarrollo local no sólo operaría al margen o a costa del desarrollo nacional, sino que además estaría asociado a una concepción concentradora y acumuladora de todo posible desarrollo, haciendo de las ciudades cualquiera que sea su escala su espacio privilegiado. Esto explica por qué "lo local" se ha convertido en un imperativo y el "desarrollo local" se ha impuesto desde los organismos de cooperación internacional, fomentando las iniciativas y reivindicaciones más particulares de las ciudades, pueblos y espacios infranacionales. Todo lo que sea desestatalizar y desnacionalizar al Estado nacional redundaría en beneficio de los poderes inter y transnacionales, de los "flujos" y "redes" de la política y la economía globalizadas.

Carente de un cuerpo teórico sólido y estable, y sin articulación con paradigma conceptual alguno, la idea de "desarrollo local" sólo puede entenderse o bien como "una nebulosa que recoge aportes procedentes de horizontes diversos", o como una práctica masivamente investida de discurso político ${ }^{4}$. En cuanto a lo primero, entre los posibles componentes del "desarrollo local" cabe enumerar "los efectos de aglomeración, la formación de una economía de proximidad, las condiciones de anclaje físico y de arraigamiento local de empresas, el impacto de programas de creación de empleos y de ingresos, las políticas de modernización del tejido interempresarial y de mejoramiento de las cualificaciones y competencias, las estrategias de incorporación y de difusión de innovaciones, la construcción de territorios para un conjunto de organizaciones y de servicios, los modos de gobernancia asociando las esferas públicas y privadas y combinando diversas fórmulas de coordinación, la creación de instrumentos institucionales..."( A. Dubresson et. al. 2005:12). Por lo que se refiere al discurso político investido en las prácticas del "desarrollo local", es posible identificar una concepción tercermundista del desarrollo autocentrado y desde las

3 Alain Dubresson \& Ives-André Fauré, “Décentralisation et développement local: un lien a repenser," Revue du Tiers Monde, n. 181, enero-marzo 2005: 9.

4 Cfr. M. Leclerc-Olive, "Décentralisation: entre dynamiques locales et mondialisation”, en M. Leclerc-Olive \&A Rochegude (dir. ), Décentralisation: entre dynamiques locales et mondialisation, Cahiers du GEMDEC, n. 27, octobre 2001; P. Aydalot, Economie régionale et urbaine, Economia, Paris, 1985. 
Lo local en cuanto simple designación geográfica -espacial de un lugar determinado y concreto ha de entenderse no sólo por sus usos actuales, sino también por los precedentes de su actual acepción.

bases, en contra de lo estatal y desde arriba; la emergencia regionalista contra lo nacionalista; el ideal de participación democrática posible a escala global contra la representación democrática.

Para compensar "el fin del desarrollo" posible ya a inicios de los años 80 "precisamente el desarrollo local muy rápido se puso de moda con una fuerte carga moral e ideológica (Venir, p. 97) y por ello dotado de una retórica muy interpelativa. Si no hay una teoría ni una práctica reales de "desarrollo local", este sólo se muestra posible al nivel de los discursos políticos con fines interpelativos o bien en cuanto expresión local de procesos de desarrollo nacional y regional, y en cuanto resultado de una combinación de factores a esca- las variables. A la pregunta de M. Vanier de cuál es el real poder económico, que disponen los actores del desarrollo local, habría que añadir una especificación: ¿en qué medida son locales tales actores y su poder económico? Ya que separar u oponer lo global y lo local resulta injustificable, sobre todo si se reconoce que lo local se articula por redes y por flujos con lo global, no pudiendo ser estas mediaciones más que nacionales, regionales e internacionales. En conclusión "lo que se ha convenido en llamar desarrollo local no es más que una nueva ideología de la acción pública para tiempos de crisis: una acción menos institucional y más flexible, que rebasa los marcos anteriores... pero que renuncia a pensar los grandes mecanismos socio-económicos" (M. Vanier, p. 99).

\section{Para una arqueología de la idea de "local"}

Un equívoco tan arraigado como extendido supone que los conceptos teóricos son los más lejanos y ajenos de la realidad, y los que menos pueden influir en ella, mientras que las nociones más simples y concretas, más descriptivas, las que mejor $d e-f i$ nen los hechos, es decir las que más limitan su comprensión, serían también las que mejor se aplican y con 
mayor éxito. Este último error ignora que los conceptos aplicados nunca son resultado de un conocimiento (real) de los hechos, sino que, más bien, responden a intereses y necesidades, posibilidades y facilidades de intervención en dicha realidad. Y, precisamente, por tal razón tales intervenciones fracasan inexorablemente, ya que son incapaces de influir y cambiar una realidad, de la que ignoran las causas y los factores o procesos de su existencia. Por el contrario, los conceptos teóricos, en la medida que comprenden y explican la realidad en sus razones y sus causas, interpretan sus sentidos, son los que mejor pueden orientar las prácticas relativas a intervenir en dicha realidad, y los únicos que logran dirigir sus transformaciones.

Dos razones determinan el valor teórico de un concepto: en primer lugar el efecto de conocimiento de sus relaciones conceptuales, ya que es sólo en relación con otros conceptos, que se demuestran sus posibilidades de comprensión y explicación; en segundo lugar, la genealogía de sus usos, puesto que la procedencia de un concepto, su "arqueología" como diría Foucault, sus orígenes y empleos más o menos teóricos o ideológicos garantizan también sus competencias explicativas e interpretativas.
Lo local en cuanto simple designación geográfica-espacial de un lugar determinado y concreto ha de entenderse no sólo por sus usos actuales, sino también por los precedentes de su actual acepción. Cuando a finales de la década de los 80 entra en crisis no sólo el desarrollo rural, sino también la misma concepción de ruralidad (incluso de lo agrícola y lo campesino), se opera un desplazamiento práctico así como conceptual hacia los centros urbanos o pequeñas aglomeraciones poblacionales insertos en el medio rural. De hecho, será a partir de ellos que se repiensan y reprograman las nuevas orientaciones del desarrollo rural convertido en desarrollo local. A este proceso ha correspondido otro de manera paralela y que se consolida en la década de los 90: la descentralización del Estado y su recentralización en los espacios-gobiernos-sociedades regionales y locales.

La descampesinización de las sociedades rurales no puede entenderse sino es en el marco de las transformaciones agrarias en todo el mundo, y de manera muy particular el creciente desfase económico entre el sector agrícola y los otros sectores de la economía. Mientras que la agricultura tiene que ser subvencionada incluso en aquellos países, donde la producción agrícola podría resultar 
viable en razón de las ventajas competitivas para su explotación y el desarrollo de su productividad (extensión latifundista de las propiedades, calidad de los suelos y favorable configuración geográfica, regularidad climática, rentable recurso del riego, tecnología y crédito, favorable acceso a mercados), la agricultura ha dejado de ser objeto de cooperación para el desarrollo en los países subdesarrollados, donde además de no estar subvencionada resulta inviable a causa de las desventajas comparativas o factores adversos para garantizar su productividad: minifundios con geografías accidentadas, baja calidad de los suelos, riesgos climáticos, ausencia o dificultad de riego, falta de tecnología y de crédito, precario y contingente acceso a mercados. Esta ha sido la principal razón por la cual las políticas, proyectos y programas de desarrollo rural se reconvertirán en el transcurso de la década de los 90 en políticas, proyectos y programas de desarrollo local, trasladando hacia los pueblos rurales o pequeños centros urbanos todas las posibilidades de desarrollo de la "sociedad rural" e incluso de los sectores campesinos residuales. Pero ésta también ha sido la principal causa, para que las sociedades rurales declinaran, se hicieran cada vez más pueblerinas, "descomunalizándose" y urbanizándose progresivamente.

De esta manera lo local se define, se forma y se consolida en la convergencia de dos procesos relativamente concomitantes: por una centralización urbana del desarrollo de las áreas rurales y una descentralización de los organismos y políticas del Estado. Pero esta formación de lo local no tiene en cuenta dos fenómenos de carácter más estructural y estructurante: la globalización y el cambio de modelo hacia una sociedad postsocietal, una "sociedad en redes" (network society) tal y como la concibe Castells ${ }^{5}$.

\section{De lo rural a lo local: la comunidad andina}

Una indagación muy somera sobre la genealogía y procedencia de la

5 Manuel Castells, La sociedad de la información. Economía, Sociedad y Cultura. 1 La sociedad en red, Alianza, Madrid, 1996. Nada tiene de casual que el nuevo modelo de concentración y acumulación capitalista a nivel global haya hecho de las ciudades y grandes urbes en todo el mundo el lugar privilegiado de todos los otros procesos concentradores y acumuladores (demográficos, tecnológicos, políticos y culturales, administrativos y de servicios). 
idea de "desarrollo local", nos conduce a considerar el carácter sustitutivo que adopta respecto del "desarrollo rural", y, sobre todo, cómo las "sociedades locales", urbanas o pueblerinas, y "poderes locales" aparecen compensando el decline de las sociedades rurales.

Hace 25 años, en 1981, se publicaban dos libros, uno en Ecuador Comunidad andina: estrategias políticas de desarrollo (CAAP, Quito), y otro en Perú, de O. Plaza y Marfil Francke, Formas de dominación, economía y comunidades (DESCO, Lima), coincidiendo ambos en el mismo interés teórico y práctico, al identificar "un campo conceptual y metodológico para comprender el funcionamiento de las comunidades andinas". No se trataba simplemente de definir y delimitar un espacio de análisis y de intervención, sino sobre todo de considerar la comunidad indígena como categoría sociológica, a partir de la cual comprender y explicar los diferentes fenómenos y procesos socioeconómicos, políticos y culturales que tienen lugar en el medio de las poblaciones indígenas de los Andes; es decir, en cuanto producidos e informados comunalmente ${ }^{6}$. Pero ya desde inicios de los 80 , se comienza a detectar, junto con las transformaciones que tienen lugar en el medio rural y agrario de la Sierra, procesos de cambio en el campesinado indígena y en las mismas condiciones de la comunidad andina ${ }^{7}$. Sin ignorar las resistencias e inercias a los cambios, y tampoco la diversidad de situaciones regionales y aun zonales, donde han tenido lugar transformaciones modernizadoras y de desarrollo, estos enfoques y otros análogos han enfatizado la tendencia hacia la proletarización del campesinado indígena, su "informalización urbana" y hasta su

6 De hecho, durante más de una década, todas las investigaciones y publicaciones del CAAP en torno a la problemática rural y campesina indígena adoptaron este enfoque comunal. "políticas de salud y comunidad andina" (1982), "estrategias de supervivencia en la comunidad andina" (1984), "la trama del poder en la comunidad"(1986), "faccionalismo, organización y proyecto étnico" (1988)," aprendizaje, conocimiento y comunicación en la comunidad andina" (1988), "medicina andina. Situaciones y respuestas" (1992).

7 L. Martínez Valle, ya a partir de su primera obra La descomposición del campesinado en la Sierra ecuatoriana Ed. El Conejo, Quito, 1980), no dejará de observar las diversas y sucesivas formas que adoptan los cambios en medio rural de la Sierra andina y del campesinado indígena: Economía política de las comunidades indígenas (CIRE, Quito, 1987); El empleo rural en el Ecuador (ILDIS-INEM, Quito, 1992); Los campesinos artesanos en la Sierra Central. El caso Tungurahua, (CAAP, Quito, 1994); Economías rurales: actividades no agrícolas (CAAP, Quito, 2000). 
progresiva caída en la mendicidad de las ciudades8.

Para entender los cambios operados en el medio rural y campesino de las comunidades indígenas hay que enmarcarlos dentro de las más amplias transformaciones de lo "rural" y de lo "agrario", e incluso al interior de la misma crisis del desarrollo nacional, que ya desde los inicios de la década de los 80 , marcará la crisis definitiva del "desarrollo rural". Son tales cambios los que permitirán, a su vez, comprender los factores que conducirán a la sustitución del anterior "desarrollo rural" por el actual "desarrollo local", pero también a los equívocos y cuestionamientos que comporta una tal sustitución.

\section{Cambios en la concepción de "ruralidad" y sus morfologías}

Fue también hace 20 años cuando en pleno auge del desarrollo rural, los proyectos DRI (Desarrollo Rural Integral) pretendían el doble objetivo de integrar los sectores rurales y campesinos subdesarrollados al supuesto desarrollo nacional, y de integrar todos aquellos factores (productivos, infraestructurales, financiero/crediticios, tecnológicos, mercantiles y de capacitación) capaces de un estructural desarrollo de los sectores rurales. Sin embargo, a partir de la crisis del desarrollo nacional, ya patentizada en la primera mitad de los 80 (1982, cuando declara la crisis de la deuda), también el desarrollo rural, muy estrechamente asociado al desarrollo agropecuario y campesino, declina y entra en crisis; y no sólo por falta de los subsidios gubernamentales, sino porque tales proyectos de desarrollo han dejado de ser "rurales" por defecto de condiciones y posibilidades de la misma agricultura andina y de las áreas de las comunidades indígenas 9 .

La noción de "rural" se ha modificado en primer lugar en razón de su desconexión con lo agrario o agropecuario y la separación creciente entre ambas categorías: una ruralidad no

8 No sólo la casi totalidad de los mendigos de las ciudades de la Sierra son indígenas, también un gran porcentaje de beneficiarios del gubernamental "bono de la pobreza", rebautizado como "bono solidario" son indígenas. Cfr. J. Sánchez - Parga, CAAP, Quito, 1996.

9 En la región del Quilotoa, provincia del Cotopaxi, donde hemos realizado la última investigación (cfr. Crisis en torno al Quilotoa. Mujer, cultura y comunidad, CAAP, Quito, 2000), hasta finales de la década de los 80 trabajaban más de 25 ONG's, organismos nacionales e internacionales, además de un DRI y un proyecto FODERUMA del Estado. En la actualidad, no quedan más que los programas PRODEPINE (financiamiento internacional con gestión indígena) y la agencia italiana de cooperación Matto Grosso. 
agrícola y una agricultura no rural. Este desdoblamiento se refuerza con otra diferencia adicional: una agricultura más rural que sigue siendo campesina, y otra menos rural y más bien empresarial. Las empresas de flores y de ciertos cultivos de consumo selectivo o producidos para la exportación se encuentran más vinculados a las áreas urbanas que al medio rural.

En cuanto categoría operativa lo "rural" sigue definiendo identidades dentro de la oposición campo / ciudad (rural / urbano). Esta oposición mantiene ciertas características inalteradas, pero no en todos sus aspectos. En el medio del campesinado indígena las identidades de origen y pertenencia rurales y comunales siguen definiendo amplios sectores, que no sólo han dejado de vivir de la agricultura, sino que la mayor parte de su vida la pasan en la migración urbana $^{10}$. Sin embargo, ya sea por la fuerza de tales vinculaciones "étnicas" o por las dificultades e impedimentos para lograr una mayor y más estable o definitiva integración en la sociedad urbana, dichos sectores de la población rural, campesina e indígena mantienen sus identidades $y$ adhesiones tradicionales. También en términos operativos el carácter disperso de los asentamientos rurales no sólo hace muy difícil la "presencia del Estado", donde siempre estuvo ausente, sino porque también la ampliación de los servicios, organismos e instituciones de la sociedad moder-

Mientras que antes las tareas agrícolas compartidas por varones y mujeres se diferenciaban en actividades masculinas y femeninas, en la actualidad casi todas las actividades agropecuarias han quedado confiadas a las mujeres en ausencia de los varones migrantes.

10 Mientras que el joven comunero migraba en la década de los 80, de entre los 16 ó 18 años de edad, en la actualidad, dicha migración se ha vuelto mucho más precoz: 14 años. Edad a la que migran también las niñas, que antes, en los 80 , quedaban al margen de la migración. Y, mientras que antes, el migrante regresaba para casarse y generalmente no volvía a migrar o al menos con la misma frecuencia, en la actualidad, el migrante sólo regresa a una edad cada vez más tardía. 
na se mantienen distantes del medio rural, y no logran superar las difíciles comunicaciones entre ambos espacios. Aun cuando tanto la masa de población migratoria como la circulación de mercancías hacen que la complementariedad urbano / rural se sobreponga cada vez más a sus distancias y oposiciones.

Una ulterior caracterización, que opone y complementa "lo rural" y "lo urbano" se refiere al alto nivel de centración de la ruralidad, expresada en la misma comunidad andina, sin que ello signifique un completo repliegue sobre sí misma, a diferencia de la centralidad que caracteriza lo urbano, el cual genera y desarrolla un campo de atracción tendiente a descentrar lo rural. Estas dinámicas imprimen a las comunidades una apertura selectiva a la modernidad, manteniendo enclaves tradicionales, de mayor inercia o resistencia al cambio. Este mismo fenómeno, que se manifiesta de distintas formas y en diversos ámbitos, explica que la agricultura conserve un peso simbólico/residual, enclave de las seguridades reproductivas, de las estrategias de subsistencia e identitarias, pero en cambio dismi- nuye su rendimiento estructural y peso productivo. Mientras que antes las tareas agrícolas compartidas por varones y mujeres se diferenciaban en actividades masculinas y femeninas, en la actualidad casi todas las actividades agropecuarias han quedado confiadas a las mujeres en ausencia de los varones migrantes.

En cuanto categoría analítica "lo rural" connota la constitución de nuevos actores sociales, de nuevas instituciones, recursos y procesos. La migración urbana no ha logrado proletarizar en un porcentaje significativo la población indígena, y mucho menos de manera definitiva; pero tampoco ha permitido su recampesinización y ruralización, tendencia ésta última que parecía dominar hace 20 años las primeras estrategias migracionales: el regreso al agro, con un capital de inversión para comprar más tierras y mejorar las condiciones de la producción agropecuaria. Más bien una elevada proporción de migrantes tiende a engrosar el sector informal urbano más precario ${ }^{11}$. Sin embargo, se ha operado más recientemente una cierta proletarización campesino/rural en las industrias

11 Un elevado número de migrantes campesinos indígenas trabajan como jornaleros, contratados por día o por semana, y muchos de ellos, tanto en Quito como en Latacunga, no como "fuerza de trabajo" sino como "fuerza de carga", en los mercados y terminales de transporte. 
agrícolas o empresas de flores, sobre todo vinculadas a las periferias urbanas que a los perímetros rurales, así como el trabajo artesanal tiende a ocupar un nicho económico intermedio cada vez más importante.

La "sociedad rural" se ha ido modificando en su misma estructura espacial por las nuevas condiciones de trabajo, medios de transporte y comunicación, siendo estas redes de comunicación, los itinerarios laborales, las intermediaciones de los pueblos con los medianos y grandes centros urbanos, y no tanto las distancias y oposiciones entre campo y ciu$\mathrm{dad}$, las que realmente organizan el mundo rural y sus formas de socialización. El desarrollo de las comunicaciones y el transporte, la circulación de nuevas mercancías y la formación de nuevos circuitos comerciales han modificado la estructura de los mercados rurales y sus flujos mercantiles: mientras que en los pequeños mercados parroquiales o comunales el volumen de productos que ingresan se ha vuelto cada vez mucho mayor al de los que egresan, los mercados intermedios cantonales también tienden a declinar. Por otra parte, el desarrollo tecnológico, la ampliación de los sectores crediticios $y$ financieros han obligado a una importante ampliación de servicios, que tienden a concentrarse en los pueblos o pequeñas y medianas ciudades, sobre todo, en aquellas regiones y zonas donde se concentra el desarrollo de una agricultura industrial y empresarial ${ }^{12}$.

La más reciente y progresiva integración de la agricultura y sociedad rural a la economía y sociedad global instaura una nueva interdependencia entre funciones y grupos, que no se reduce al aspecto cultural, sino que posee dimensiones más amplias, económicas y políticas: lo que comporta una reorganización social del espacio, incluyendo una mayor interpenetración territorial. Tal fenómeno de "urbanización" de la "sociedad rural" responde a una "difusión

12 Para estimar los cambios operados a partir de las más recientes observaciones cabe tomar como referencia el estudio de Raymon J. Bromley, El papel de la feria semanal en el desarrollo rural, JUNAPLA, Quito, 1975 (mimeo); reeditado en "Traditional and modern Change in the growth of system of market in highland Ecuador" en Market-Place:Periodic Markets, Hawkers and Traders in Africa, Asia and Latin America, University British Columbia, Vancouver, 1978. Mientras que el crecimiento y multiplicación de los mercados rurales corresponde en la década de los 70 hasta los 80 , a una expansión de la producción agricóla campesina, la actual reducción de dichos mercados y ferias resulta del declinar de la producción agopecuaria en dichas zonas. 
de comportamientos y valores", que Castells traduce con el nombre de "cultura urbana". Ambas dimensiones se combinan y condicionan mutuamente, al divesificar y complejizar territorialmente las actividades generando una combinación múltiple de relaciones urbano/rurales: vivir en el campo y trabajar en la ciudad, vivir en la ciudad y trabajar en el campo, vivir y trabajar en la ciudad manteniendo relaciones familiares y comunales en el campo, y viceversa; vivir y trabajar simultáneamente en la ciudad y en el campo. Tal morfología de situaciones corresponde a modelos y estrategias económicas tan diversas como diversas son también las configuraciones socio culturales, que al mismo tiempo que homogeneizan lo urbano y lo rural, introducen en ambas esferas una creciente heterogeneidad.

Según esto, cabría suponer que el fin de las "sociedades rurales", incluso a mediano y largo plazo, no significa el fin de "lo rural", el cual considerado en cuanto espacio social no distinto ni compartimentalizado, sino como segmento de la sociedad global, podrá seguir siendo pensado como un espacio singular susceptible de procesos y topologías diversas: desde el crecimiento de pueblos intermedios, tanto centros parroquiales como cantonales, hasta la creciente atrofia de otros con el consiguiente despoblamiento y pérdida de importancia económica y política.

Todas estas alteraciones, nuevas interdependencia y penetraciones entre "lo rural" y "lo urbano" no pueden ser plenamente comprendidas y explicadas sin referencia a las transformaciones y modernización del Estado. De un lado, a diferencia de los países desarrollados, donde el sector agropecuario se encuentra sólidamente subvencionado por el Estado (caso EE.UU. y Unión Europea), el fin del "desarrollo rural" y de las políticas agrarias de los gobiernos nacionales han abandonado el sector agrario a su suerte más incierta; por otro lado, menos por iniciativas y planificación del mismo Estado nacional y más por inducciones foráneas o por dinámicas generadas desde las mismas regiones, el "desarrollo local" ha sido interpretado y protagonizado desde los gobiernos locales, y desde una perspectiva urbana, no agraristas ni campesina ${ }^{13}$. Desde esta nueva perspectiva asistimos a una in-

13 En esta dirección se han orientado las ayudas de la cooperación internacional, y muy en particular los programas del FMI y del Banco Mundial. 
versión del paradigma vigente hace 20 años (los DRI): en lugar de pensar el desarrollo (rural) como una integración de sectores agrarios y campesinos al desarrollo nacional (urbano), el "desarrollo local" se planifica como una extensión desde los centros locales (ciudades o pueblos intermedios) hacia sus periferias rurales, los interland de las comunidades campesinas, enfatizando y reforzando la descentralización de los recursos estatales y su gestión.

Si se toma en serio la hipótesis de la "sociedad en redes" (network society) como nuevo modelo de sociedad global, que tiende a transformar los espacios socio-locales en "espacios de flujos", también "lo rural" e incluso en su nueva versión de "local" habrá de ser repensado en todo aquello que más lo caracterizaba: la interacción social y la organización institucional atendiendo a su contigüidad territorial, cuando "la mayoría de los procesos dominantes, que concentran poder, riqueza e información se organizan en espacios de flujos"14. En el marco de estos cambios de las "sociedades rurales" y de los nuevos procesos sustitutivos de los espacios territoriales (rurales y locales) por los espacios de flujos, surge la pregunta sobre qué ha ocurrido con las "sociedades comunales" del campesinado indígena andino en el transcurso de las dos últimas décadas.

\section{La comuna indígena y sus descomunalizaciones}

A este interrogante la primera respuesta es la diversificación de estrategias y reacciones a dichos cambios. Aunque cada comunidad andina fue siempre una ecuación irrepetible y distinta de sus vecinas, siempre era posible definir numerosos rasgos comunes, que les conferían una cierta homogeneidad por encima de las diferencias, en la actualidad, la heterogeneidad de estrategias $y$ de transformaciones parece imponerse más bien sobre los rasgos compartidos. Más allá de una caracterización muy simplificada que diferencie un modelo de comunidades que, en mejores condiciones para responder a los retos acturales, adoptan una orientación modernizadora, mientras que otras comunidades incapaces de entrar por la vía de la modernización resisten a los cambios, se requiere más bien reconocer la diversificación de estrategias y la fragmen-

\footnotetext{
14 M. Castells, La era de la información. Economía, Sociedad y Cultura. Il. El poder de la identidad, Alianza Ed. Madrid, 1998: 148.
} 
tación de sectores y situaciones. De manera más precisa cabría distinguir, por un lado, un doble proceso de "descomunalización" modernizadora y sin modernización, y por otro lado una recomunalización así mismo emprendedora de modernización o resistente a ella.

\section{Pero esta plena articulación a la economía y socio-cultura urbanas no impide que se mantenga la estrecha cohesión e identidad comunales.}

La descomunalización modernizadora no comporta una destrucción, sino una transformación de la sociedad comunal, la cual se vuelve cada vez más funcional e interdependiente y hasta integrada a las "sociedad societal" urbana. Los cambios en este modelo se realizan fundamentalmente por una relativa desagrarización de las estrategias productivas y reproductivas, por una amplia integración al mercado laboral (ya sea en las empresas e industrias agropecuarias o al sector formal urbano) y al mercado de bienes y servicios, una creciente movilidad socio-espacial (con el consiguiente predominio de la exogamia, muy sintomática de la apertura cultural de las comunidades). Pero esta plena articulación a la economía y socio-cultura urbanas no impide que se mantenga la estrecha cohesión e identidad comunales. Más aún, muchas de las nuevas formas de organización (cooperativas, asociaciones, juntas, comités...) coexisten con el modelo de socialización comunal. Lo que tampoco excluye que en no pocas ocasiones estas institucionalidades modernas se superpongan con las tradicionales, puedan entre ellas restarse competencias y autoridad, pero no necesariamente tales tensiones o conflictos compor$\tan$ incompatibilidades ${ }^{15}$.

Hay ciertos procesos de modernización, que sin llegar a destruir la sociedad comunal pueden a mediano y largo plazo erosionar las solidaridades e interdependencias más profundas de la sociabilidad y estra-

15 Este modelo de descomunalización modernizadora ha sido objeto de una investigación hace algo menos de una década en tres zonas muy representativas del fenómeno: Calderon, Tabacundo y Cayambe: cfr Transformaciones socio culturales y educación indígena, CAAP, Quito, 1993. 
tegias más compartidas de la comuna, como puede ser el caso de un desarrollo de la competitividad en uno o varios sectores económicos ${ }^{16}$. Mientras que la descomunalización modernizadora es un fenómeno propio de zonas de significativo desarrollo rural (no necesariamente agropecuario), y de fuerte influencia urbana (por cercanía de la ciudad o crecimiento de pueblos grandes e intermedios), una situación simétricamente opuesta tiene lugar en áreas marginales y distantes de la influencia urbana y de gran depresión agraria: la descomunalización sin modernidad. Este modelo de descomunalización modernizadora, el que quizás con mayor propiedad habría que denominar modernización comunal, se funda en un principio, que bien podría ser objeto de generalización, y según el cual, un proceso de modernización, capaz de refuncionalizar objetos, prácticas e instituciones tradicionales, lejos de tener efectos destructores, se consolida a la vez que refuerza la cultura del grupo.
Un proceso diferente de descomunalización sin modernización tiene lugar en aquellas zonas de comunidades campesinas indígenas, que distantes de los centros urbanos y en áreas de subdesarrollo rural y depresión agropecuaria, acusan los impactos de una modernización sin lograr que dichos impactos puedan ser asimilados comunalmente, transformando y modernizando las estructuras y cultura comunales. Se trata, en general, de comunas que sufren una sangría demográfica por efecto de una migración cada vez más precoz de varones y mujeres, y de un regreso cada vez más tardío e incierto de los migrantes. Esta deserción poblacional, por falta de las mínimas condiciones de reproducción y sin perspectivas de futuro, que adopta la forma de una exclusión tanto familiar como comunal, comporta una ruptura de vínculos, que se traduce en deslegitimaciones y violencias dentro y contra de las mismas familias y comunidades ${ }^{17}$.

16 Cfr. Rudi Colloredo, “Artesanía, competencia y la concertación de la expresión cultural en las comunidades andinas", en Ecuador Debate, n 52, 2001: 135-150. El autor llega a distinguir una competitividad tradicional, más enmarcada y condicionada por una fuerte estructura y cultura comunales, y una competitividad capitalista o moderna, que con el tiempo tiende a fracturar las redes de vínculos y solidaridades de la comunidad.

17 Hemos ampliamente estudiado este modelo en una investigación reciente: cfr Crisis en torno al Quilotoa. Mujer, cultura y comunidad. CAAP, Quito, 2000. 
Una sorda y poco visible disolución de los vínculos del parentesco se expresa también en matrimonios cada vez más contingentes y efímero, y en un fácil abandono de los hijos a los cuidados de los parientes. La falta de trabajo y de tareas colectivas, $y$ el gran ausentismo de varones y mujeres, vuelve raras e innecesarias instituciones como la minga, actividades compartidas, las prácticas tradicionales de la reciprocidad y el intercambio (randi-randi, maquita manachi), todo lo cual contribuye a que la comunidad deje de ser percibida como un soporte común para las estrategias familiares o individuales, apareciendo más bien ante los mismos comuneros como un impedimento asociativo, que más bien constriñe y limita las iniciativas privadas y proyectos particulares. La declaración que a veces se escucha, "no somos comuna, sino indios libres" es muy reveladora de esta nueva conciencia y valoración de la comunidad ${ }^{18}$.

Si por un lado la migración masiva hacia las ciudades o regiones de la costa refuerza las desidentificaciones comunales, por otro lado, la misma negación de los valores culturales tradicionales, muy asociados al rechazo de un medio de vida que impide toda sobrevivencia, hace extremadamente permeables estos comuneros y comunidades a los imaginarios culturales urbanos y mercantiles. Lo que por otra parte agudiza tensiones y conflictos de repliegues culturales, que suelen adoptar con frecuencia formas de gran intolerancia.

Muy exponencial de esta crisis de comunidad es la que afecta a las autoridades y poder representativo de los Cabildos comunales. Rebasados por las formas e intensidades de los nuevos conflictos y violencias al interior de la familia y la comuna (el nuevo fenómeno de las bandas juveniles), sin capacidad de negociación y mediación, despojados de ciertas competencias asumidas por los Tenientes políticos o las nuevas Juntas parroquiales, las tradicionales dirigencias de la comunidad han perdido competencias y funciones tanto internas como externas. De otro lado, la hipertrofia organizacional, con la aparición de numerosas OSG (organizaciones de segundo grado) integrando las comunidades de diferentes zonas o parroquias y cantones, han despojado a las comunida-

18 La formula recibe toda su fuerza significativa de su carácter evocador de un pasado en el que los "indios libres" eran indios de comunidad por oposición a los "indios de hacienda". 
des y sus Cabildos de la "soberanía" que antes gozaban, aun cuando a través de las nuevas instancias organizativas puedan haber ganado mayor poder y representación a escala provincial y nacional.

Esto mismo parece haber influido en una nueva representación de la comunidad, la cual estaría declinando en tanto modelo de sociedad y de socialización, para convertirse en un modelo asociativo y organizativo, llegando a concebirse y planificarse como jurisdición territorial, con sus propias delimitaciones político-administrativas, contradiciendo al carácter tradicionalmente abierto de lo comunal a relaciones intercomunales, de parentesco, de intercambios e interdependencias, con otros ayllus de comunidades vecinas; lo cual permite que las redes y vínculos comunales entre los ayllus atravesara y sobrepasara las delimitaciones de la misma comunidad"19. Esta "descomunalización" destructora de socialidad comunal no significa el fin o la desaparición de las comunidades, sino una precarización de los vínculos so- ciales a su interior, un debilitamiento de sus formas asociativas, de las cohesiones y dimensiones colectivas como un recurso para las familias y los individuos. Cabría concluir que son las condiciones de empobrecimiento y pérdida de recursos productivos y materiales lo que vuelve extremadamente frágiles estas comunidades bajo los impactos de una modernidad tan ajena como distante.

Lo que de común comparten ambas "descomunalizaciones", con y sin modernización, es que la sociedad comunal, las actividades colectivas, la participación en estrategias y proyectos comunes, las interdependencias entre familias y miembros dejan de ser un soporte para convertirse en un limitante u obstáculo para las estrategias particulares y privadas, ya sea en términos de su desarrollo o de su supervivencia. Por el contrario, los otros dos modelos de "comunalización" con y sin modernidad, coinciden en el hecho que la comunidad, en cuanto recurso social y referente de identidad sigue siendo un apoyo para las actividades y estrategias de

19 Es importante recordar al respecto, por su extraordinaria "modernidad", que en los Andes la tradicional organización social del espacio se fundaba en la combinación de un doble eje: la verticalidad territorial que adoptaba el asentamiento de cada ayllu, cuyas familias se distribuían en diferentes pisos ecológicos, estableciéndose entre ellos el flujo y circulación de productos y mujeres, y la horizontalidad_territorial de las Ilajtas o poblados, donde coincidían diferentes ayllus, compartiendo la contigüidad de un mismo espacio de circulación de servicios y fuerza de trabajo. 
las familias, grupos e individuos, ya sea en sus estrategias de desarrollo (en el caso de la modernización de la comunidad) como en sus estrategias de supervivencia (caso de la comuna tradicional).

Por modernización de la comunidad puede entenderse una categoría relativamente poco numerosa de comunas campesinas indígenas, que sigue reproduciéndose en base de sus recursos agropecuarios, y cuyo desarrollo se sustenta en la suficiente disponibilidad y calidad de tierra y de otros recursos colectivos, que garantizan una exitosa explotación de las condiciones rurales de dichas comunas. Esto mismo permite la combinación de estrategias comunes con otras de desarrollo privado, propias de cada familia o grupo. Mientras que la descomunalización modernizadora termina supeditando excesivamente las instituciones, relaciones sociales y prácticas comunales a las iniciativas y dinámicas más privadas y a los proyectos más particulares, en este otro modelo los factores de modernización instrumentalizan pero también refuerzan los recursos tradicionales de la comunidad, al mismo tiempo que estos sirven de soporte para la implementación de nuevas prácticas $^{20}$.

Según esto, es la misma cohesión social de la comunidad, la que garantiza las mejores condiciones para la implementación y desarrollo de las iniciativas más modernizadoras. De hecho todos los factores que convergen en reforzar el desarrollo agropecuario y rural de estas comunidades (pleno acceso y uso de la tierra, aprovechamiento de las potencialidades de riego, adopción tecnológica, disponibilidad de crédito y articulación al mercado), al mimo tiempo que consolida su ruralidad, evitando la migración y proletarización campesinas, da lugar a la creación de modernas instituciones (cooperativa, crédito, servicios...), que lejos de competir con las comunales, tienden más bien a un mutuo reforzamiento. Más aún, esta modernización de la comunidad llega incluso a resolver conflictos y tensiones más propios de su cultura tradicional, y que pudiera re-

20 En una investigación anterior (cfr. Exitos y fracasos de los pequeños agricultores en experiencias de intensificación de la producción y conservación de recursos naturales en los Andes ecuatorianos: estudios de casos sobre el análisis de las causas, FAO/CELA, Quito, 1995; Doc. CAAP, 1996) se pudo observar cómo la "minga"y el "prestamanos" se combinan con el pago de jornales, reforzando la reciprocidad en una práctica de intercambio muy importante: la cosecha diaria de cebolla en la comuna de Colta Zambrano para su comercialización en los mercados de Guayaquil. 
sultar un impedimento para dicha modernización ${ }^{21}$.

Quizás el factor más determinante de este modelo de comunidad reside en las posibilidades de seguir reproduciendo una estrategia agropecuaria y/o artesanal que consolida las condiciones de ruralidad, con la que tan estrechamente se identifica la comunidad andina, pero sin marginarla del desarrollo regional y nacional. No siempre se requiere una modernización y desarrollo excesivamente exitosos para que la comunidad pueda entrar en una dinámica de modernización, y ni siquiera es necesario que un desarrollo regional, para que la comunidad pueda beneficiarse potenciando sus propios recursos y estrategias agropecuarias; basta que éstas garanticen una cierta rentabilidad 22 .

La comuna tradicional es aquella que, en parte marginal a los procesos de cambio y modernización, y en parte sujeta a ciertas inercias y resistencias, logra mantenerse en una
Como ocurre con todas las tipologías, también estos modelos de comunidad, aun a pesar de las referencias a casos y ejemplos concretos, más que caracterizar comunidades, sólo permite identificar tendencias y racionalizar ciertos procesos, sin pretender definir diferencias claras y fijas entre ellas.

precaria supervivencia a partir de sus recursos agropecuarios y rurales. Pero tampoco sufre las rupturas de una exclusión/migración excesiva, ni los impactos de aquellos factores de la modernidad que más pudieran desestructurarla (diferenciación interna o desvaríos y tensiones cultura-

21 La comunidad de Colta Zambrano fue la primera comunidad indígena, junto con otras 4 empresas agrícolas mestizas, que contrató la privatización de los servicios del Ministerio de Agricultura en 1995, superando tradicionales "faccionalismos" ha resuelto dos grandes problemas de la comuna tradicional: la borrachera y los enfrentamientos entre católicos y evangélicos.

22 Este sería por ejemplo, el caso de la gran comuna de Maca, en la provincia del Cotopaxi, que en más de una ocasión sirvió de testigo o referente comparativo, para el estudio de las comunas de la zona del Quilotoa. Maca es considerada una comunidad próspera, aun sin contar con un desarrollo agropecuario y mercantil, como el que ofrecen algunas de las comunidades de Colta. 
les). Es posible que esta género de comunidad tradicional responda a un modelo residual, o transitorio y contingente, que oscile entre una $u$ otra forma de descomunalización. $Y$, sin embargo, quizás esta categoría de comunas consideradas tradicionales, porque hacen de su cultura, prácticas y relaciones tradicionales, una suerte de capital y estrategia de supervivencia, siga siendo la más numerosa en la Sierra ecuatoriana.

Lo que analíticamente puede ser pensado como distintas modalidades de "tradicionalismo" en la comuna tradicional parece coexistir en cuanto formas o funciones que adopta la cultura indígena tanto para preservar la sociedad comunal como para resistir a los cambios de la modernidad o adaptarse a ellos. En este sentido, la sociedad y cultura comunales tratan de "salvaguardar valores, modelos y prácticas arraigados en la continuidad", al mismo tiempo que "mantienen instituciones, formas y modos de relación social, cuyo contenido se ha modificado", mientras que en otros casos dicha cultura y tradición o bien son empleados como expresiones de re- sistencia y oposición a los cambios, o bien entran en un proceso de bricolage con nuevos elementos ${ }^{23}$.

Como ocurre con todas las tipologías, también estos modelos de comunidad, aun a pesar de las referencias a casos y ejemplos concretos, más que caracterizar comunidades, sólo permite identificar tendencias y racionalizar ciertos procesos, sin pretender definir diferencias claras y fijas entre ellas. En este sentido, es muy difícil demarcar los perfiles entre la comuna tradicional y la descomunalización sin modernidad, o entre la descomunalización modernizadora o la modernización comunal, considerando que entre estos cuatro modelos no hay una precisa solución de continuidad. Dichas características se vuelven todavía más complejas, si se tiene en cuenta que dentro de una misma comunidad pueden encontrarse "mitades" o sectores y grupos tan diferentes, que algunos de ellos correspondan más a otro de los modelos que al que pertenecen. Otro elemento de complejidad, que atraviesa estas tipologías duales, pero, que penetra también sus distintas dinámicas y proyectos,

23 Cfr. G. Balandier, Anthropologie politique, PUF, Paris, 1967; Le détour, Fayard, Paris, 1985: 167. Estos distintos tradicionalismos, "fundamentalista", "formal","de resistencia" o "pseudo-tradicionalismo", analizados por Balandier se pueden encontrar en combinaciones y con énfasis muy diversos en una misma comuna tradicional. 
desde los más particulares hasta aquellos de grupos y sectores de cada comunidad, es lo que hemos denominado su doble estructura normativa, vertebrada por dos órdenes de interacción: el orden simbólico, que corresponde a una visión más idealizada que la sociedad comunal posee de sí misma, y el orden estratégico, donde las exigencias y estímulos de la realidad apremian y hasta urgen los cambios y adaptaciones.

Si hemos partido de un análisis general de los actuales procesos y transformaciones que afectan las nociones y representaciones de "lo agrario" y "rural", para mejor encuadrar y entender los cambios operados en la tradicional comunidad campesina, quizás sea necesario reconsiderar de nuevo ahora en qué medida lo agrario y lo rural en las regiones de la Sierra andina se encuentran atravesadas por esa microfísica tan compleja de las comunidades, que si bien participa de los cambios más amplios, mantiene también una relativa distancia y marginalidad respecto de ellos, sujetas a sus propias dinámicas internas.

\section{En conclusión, ¿qué es lo local?}

La comunidad andina nunca fue un territorio ni se identificó territorialmente, ni tuvo una definición o adscripción territorial, aun cuando combinara diferentes referencias territoriales: a) mientras que cada " $a y$ llu” o grupo endogámico de parentesco ampliado se distribuía en diferentes territorios con asentamientos familiares en pisos ecológicos más o menos distantes, y entre los cuales circulaban los intercambios de productos y mujeres, b) "ayllus" diferentes compartían un mismo territorio, la "llajta", donde se intercambiaban servicios y fuerza de trabajo; c) al mismo tiempo "ayllus" y "llajtas" coincidían en asentamientos multiétnicos o "mitma" (en minas, emplazamientos urbanos y costeños) para complementar y diversificar sus recursos y economías. Esta tradicional geometría variable de lugares contiguos y distantes adopta nuevas formas en la actualidad, cuando muchas comunas son tan rurales serranas como rurales subtropicales, o rurales y urbanas a la vez, ya que no sólo combinan un doble asentamientos, sino también condiciones de reproducción económica y cultural tan rurales como urbanas.

Según esto las comunidades indígenas no son "locales" en razón de una identificación o fijación territorial, sino porque en términos analíticos y operativos, se organizan en redes y flujos de relaciones, productos y servicios, que se comple- 
mentan y circulan, reproduciendo al nivel local la diversidad y diferencias y particularidades, de lo que al nivel global adopta formas homogéneas y comunes.

Son estas diversificaciones y heterogeneidades, todos éstos correspondientes procesos de complejización, lo que debería ser pensado como "local”; más que una identificación microfísica de la sociedad se trata de una categoría analítica e interpretativa, pero también de intervención social. Si por el contrario se hace de "lo local" una simple escala territorial, de pueblos más o menos grandes o de ciudades más o menos pequeñas, para pensarlo desde lo micro-urbano, adoptando a esta escala los proyectos de desarrollo, programas de descentralización administrativa, los planes de gestión política, se incurre en el equívoco y hasta en la torpeza de sustituir lo rural por lo microurbano, desconociendo ese fenómeno nuevo de "lo local", que más bien debe ser pensado y tratado desde "lo global" y en correspondencia con "lo global" (para también poder pensar y tratar lo global desde lo local).
A medida que la investigación sobre los cambios operados en la comunidad andina "veinte años después" ponía de manifiesto las nuevas formas que adoptaban los procesos migracionales con sus nuevos flujos, volúmenes y composición social; los fenómenos de identificación y desidentificación, de reconocimiento y desreconocimiento, repudios y hostilidades culturales; los fracasos de la interculturalidad provocados precisamente por programas y políticas de interculturalidad; la desintegración de la familia indígena con sus diferentes ejes parentales (ausencia de padre, quiebras matrimoniales, orfandades infantiles...) con sus consiguientes violencias; los cambios en la producción, circulación y participación de poderes políticos y de autoridad; todos estos fenómenos, entre muchos más, constituían la versión local de aquellos que con una visibilidad macrofísica caracterizaban la globalización.

Serge Latouche se muestra muy explícito: no existe la sociedad global y por consiguiente tampoco existe la sociedad local; lo local y global son categorías analíticas y operativas ${ }^{24}$; si

24 "No hay verdadera sociedad global, no es seguro que haya jamás alguna, ni que sea deseable... Los principales problemas vienen de que tampoco hay verdaderas sociedades locales" (S. Latouche, La déraison de la raison économique, Albin Michel, Paris, 2001: 145). 
lo global penetra lo local, este atraviesa aquél. Lo "local" y lo "global" no son más que espacios de transposiciones recíprocas, y por consiguiente no pueden ser pensados ni tratados o intervenidos más que en correspondencia.

La actual categoría analítica_de "lo local" presupone que las distancias y diferencias espaciales que separaban lo "urbano" y lo "rural" se han acortado o abolido en razón de los amplios e intensos intercambios, comunicaciones, "flujos" de personas, mercancías, mentalidades, productos e imaginarios culturales; en este sentido, "lo local" en cuanto $c a$ tegoría operativa debería precisamente identificar en cuanto ámbitos u objetos de intervención tales "flujos" y "redes", interdependencias, interacciones e intercambios, que son los que realmente definen el carácter "glocal", que en la actualidad adopta la circulación de información, riqueza y poder.

Sin embargo, lo que ocurre es una situación compleja, de transición o tiempos mixtos, donde las distancias y territorialidades que diferencian lo rural y lo urbano no han sido todavía plenamente integradas a los "espacios de flujos" y "espacios de redes". Esto puede dar lugar a un equívoco: conceptualizar y tratar "lo local" desde los espacios urbanos, de las ciuda- des intermedias y pueblos (considerando lo "local" como efecto de descentralización y descomposición de lo "nacional"), en lugar de pensar y trabajar lo local no desde una supuesta territorialidad imaginaria, sino desde los flujos, intercambios y comunicaciones, que configuran un nuevo y determinado espacio, donde lo urbano/rural se encuentre integrado; pero también desde las diversidades, heterogeneidades y complejidades, que caracterizan "lo local" en diferencia de "lo global".

En conclusión, no cabe pensar "lo local" como una simple sustitución de "lo rural", con su consiguiente transformación en lo "microurbano", sino como una nueva mirada, una nueva categorización, para pensar y tratar tanto lo rural como lo urbano, desde esa nueva dimensión de la globalización, en parte en correspondencia con lo global y en parte como efecto de los procesos globales. Según esto, cabría entender el "desarrollo local", no tanto como un desarrollo de los pueblos y ciudades intermedias, ni tampoco como un desarrollo desde ellos, sino un desarrollo desde los intercambios y comunicaciones en un determinado espacio; en otras palabras, integrar "lo local" a la "sociedad de flujos" y a la "sociedad en redes" (network society), o bien reproducir y desarrollar estas 
morfologías de la globalización a escala local.

Finalmente, habría que concluir preguntándose si "lo local" no es más bien y precisamente ese paradigma de la desterritorialización, el lugar imaginario donde se revelen todos los desarraigos territoriales, donde mejor se expresan los efectos de la pulverización espacial resultante de la implosión de los territorios nacionales, lo únicos que durante más de cinco siglos habrían marcado y delimitado todos los procesos y fenómenos sociales: desde las pertenencias históricas hasta las identidades culturales, lingüísticas, y religiosas, pasando por la economía y mercado. "Lo local" aparecería entonces como la categoría de la desterritorialización de todos estos fenómenos y procesos; y por consiguiente, no sería ni

\footnotetext{
Esto es precisa y específicamente lo que define lo local como un campo de fuerzas y de flujos, y sólo dentro de este sistema de lógicas ‘ y de fuerzas puede comprenderse y explicarse lo local.
}

tan exacto, ni pertinente restringir el planteamiento de "lo local" como una transformación de "lo rural".

\section{Hacia una sociología global de lo local}

El concepto de local ha sufrido de este doble equívoco: se ha optado por su acepción más empírica, positivista y funcional, que se limita a designar un lugar muy bien definido espacial y geográficamente, a la vez que se ignora que lo local puede entenderse como una categoría espacial, pero que no define un lugar determinado y concreto en términos geográficos sino en otros aspectos.

En este sentido lo local deberá entenderse más bien como un concepto teórico capaz de comprender y explicar todos los fenómenos, que tienen lugar en un espacio determinado, pero que relevan de otras escalas o dimensiones espaciales. Por esta razón lo local corresponde pero de manera simétricamente opuesta a lo global, y no puede entenderse sino en referencia a este; pues tampoco lo global designa un lugar geográfico determinado y concreto, sino más bien una dimensión espacial, en la que convergen todos los flujos, fuerzas e intereses de los procesos locales. Según esto lo local se manifiesta como un espacio donde se expresan de manera 
concreta, múltiple y diversa o diferenciadamente los fenómenos globales, mientras que lo global es la dimensión o escala donde se amplifican, en la que convergen, se unifican y generalizan toda la diversidad y diferencia locales. En otras palabras, lo local ha de ser pensado en cuanto complementario de lo global, ya que ambas dimensiones o categorías espaciales enmarcan todos los fenómenos y procesos que tienen lugar en el mundo entero así como en cada lugar del mundo.

De acuerdo a estos planteamientos lo local es un fenómeno nuevo, propio de la moderna sociedad postsocietal, donde los espacios de flujos y fuerzas se imponen y dominan sobre los espacios lugares. Por ello, observación ésta muy importante, son los flujos los que definen los espacios y no al contrario (Castells, I, p. 468). Aun cuando las relaciones entre espacio de flujos y espacio de lugares, entre la dimensión global de los fenómenos y procesos y su dimensión local nunca estén predeterminadas por muy simultaneas que sean (o.c., p. 477). La idea de "flujos" expresa muy acertadamente cómo los intereses, fuerzas e informaciones fluyen entre lo local y lo global, atravesando e interconectando todos los espacios intermedios: regionales, nacionales e internacionales.
Es evidente que las personas viven todavía y seguirán viviendo en lugares, pero son todos los flujos de fuerzas e intereses e informaciones, que actúan en dichos lugares, pero que se generan y circulan por otras dimensiones espaciales-globales (en todo el mundo, entre continentes, regiones y naciones), los que condicionan la vida de esas personas así como definen la naturaleza local de dichos lugares: "la dominación estructural de la lógica de los flujos modifica fundamentalmente el sentido y dinámica de estos lugares" (o.c., p. 480).

Se puede operar una tensión y conflicto, pero, también una suerte de esquizofrenia estructural entre ambas lógicas espaciales: la de los flujos y la de los lugares, aunque siempre bajo la tendencia dominante del espacio de los flujos sobre el espacio de los lugares. Esto es precisa y específicamente lo que define lo local como un campo de fuerzas y de flujos, y sólo dentro de este sistema de lógicas y de fuerzas puede comprenderse y explicarse lo local. Y no simplemente como un lugar amorfo e inerme. Mientras que el anterior modelo de sociedad se podía suponer que los fenómenos microsociales condicionaban los macrosociales, hoy es preciso reconocer que lo global determina lo local. Según esto lo local se halla tan simétricamente opuesto 
a lo global como articulado en estrecha correspondencia: ninguno de las dos dimensiones es pensable sin la otra, ya que es el sistema de flujos entre ellas lo que las constituye tanto en su polaridad como en sus interacciones e interdependencias. Lo cual conduce a la conclusión, en términos muy estructuralistas, que tanto lo local como lo global han de ser pensados a partir de las redes de flujos, que interactúan entre ellos, y no al contrario.

La categoría de local en su correspondencia e interacción con lo global permite superar la convencional y funcionalista diferencia entre lo macro-social y lo micro-social en cuanto aspectos o dimensiones analíticas distintas de la sociedad, debiendo reconocer que no es posible una completa y coherente comprensión de ambas realidades y de cada una de ellas, sino a partir de sus recíprocas relaciones, de tal modo que se puede entender mejor lo micro-social desde lo macro-social, y este desde aquél. No se trata propiamente de planos superpuestos de la realidad, sino las diferentes escalas que adoptan los fenómenos y procesos sociales en el mundo actual. Así mismo sería necesario plantear que únicamente desde una explicación global de los fenómenos locales se permite una mejor actuación a nivel de éstos, de igual manera que desde una explicación local de los fenómenos globales se garantizaría también una mejor intervención en éstos.

Ahora bien ¿cómo los flujos definen lo local? ¿De qué manera los flujos de información, de intereses y fuerzas, recursos, productos y mercancías... que circulan por distintos niveles espaciales entre lo global y lo local configuran esta última realidad? Tomemos el caso de una zona o ciudad de la región amazónica ecuatoriana. El carácter local de tal zona, ciudad, pueblo o población se encuentra definido en primer lugar por un escenario petrolero, al que fluyen los intereses petroleros de toda la región, los nacionales, internacionales y mundiales; en segundo lugar por un escenario ambiental o ecológico de extraordinario interés y riesgo no sólo para la región y para el país, sino también para todo el subcontinente sudamericano y hasta para todo el mundo; en tercer lugar, un escenario étnico en el que así mismo se cifran intereses y preocupaciones tanto regionales y nacionales como internacionales y globales, ya que la cuestión étnica de los pueblos amazónicos es parte importante de la problemática indígena en todo el mundo; incluso cabe pensar en un flujo poblacional de migrantes y "desplazados" no sólo regionales y nacionales sino también 
internacionales, como parte de ese fenómeno más global de masas migratorias movilizadas por todo el mundo. Finalmente, se podrían añadir otros escenarios que si no aparecen hoy tan relevantes pueden llegar a serlo en el futuro: el escenario de la droga y el narcotráfico y el escenario guerrillero; ambos atravesados por flujos de fuerzas e intereses que circulan por los distintos niveles espaciales entre lo global y local.

De esta manera lo local queda comprendido en cuanto espacio de flujos, que condicionan e incluso determinan el espacio lugar; y ese espacio local de la Amazonía no puede ser entendido de manera completa y coherente al margen de los diferentes flujos que se localizan en él. Cada "flujo" presenta siempre o bien una cierta complejidad o bien contradicciones internas. Así, por ejemplo, los intereses y poderes de la compañías petroleras expresan, a la vez que sirven de soporte la geopolítica petrolera de EE.UU., los intereses petroleros del Estado ecuatoriano al mismo tiempo que le proporcionan una relativa autonomía y soberanía energéticas y financieras contribuyen a reproducir su dependencia económico política respecto de la Banca global a través del endeudamiento y del pago de la deuda externa.
En términos prácticos y operativos es posible verificar el mismo tipo de análisis y comprensión de lo local. Un proyecto de desarrollo, que integra un conjunto de programas destinados a una determinada zona o localidad (una parroquia o un cantón), y cuyos objetivos pueden abarcar desde riego, tecnología y crédito hasta educación, promoción de género e infraestructura vial, pasando por capacitación administrativa, etc., y todas estas actividades pueden tener efectos visibles en cada uno de sus programas de desarrollo y promoción. Sin embargo, la eficacia de todos ellos, puede quedar en parte muy limitada y en parte puede resultar muy contingente y efímera, en la medida que son incapaces de neutralizar todos los factores constringentes o factores restrictivos (que "se representan" en cuanto "externos" al lugar), que ejercen su influencia en cada uno de los ámbitos de dichos programas $\mathrm{y}$ actividades.

Un ejemplo muy simple, concreto y real: todos los mejoramientos educativos se encontrarán limitados por el sistema escolar nacional, por los recursos presupuestarios anuales, sus debilidades pedagógicas y curriculares, por la formación de los maestros, por una concepción de la misma escuela, por las grandes 
transformaciones que definen hoy una nueva relación con el conocimiento, la información y el pensamiento. Una situación análoga cabe considerar en el caso del desarrollo de la agricultura, de su mayor rentabilidad, muy condicionada por los precios de los productos agrícolas en los mercados locales y regionales, a su vez condicionados por la economía nacional y ambos por los efectos del TLC, etc. Cabría suponer que hay lugares en parte tan "locales" a nivel de escala y en parte tan aparentemente aislados y autónomos, que resultaría más difícil pensarlos en cuanto espacios de flujos e influidos por procesos y fenómenos de carácter más global. Y, sin embargo, habría más bien que sostener todo lo contrario: son precisamente estos lugares, cuya localidad debería ser más pensada en cuanto definida por los espacios-flujos, y mucho más condicionada por la globalidad.

Baste para confirmar esto como ejemplo uno de los resultados de una investigación reciente en una región de comunidades indígenas en la sierra central del Ecuador. En primer lugar, conflictos de identidad cultural, que se supondrían más bien propios de aquellos espacios de una gran confrontación étnica con arraigos históricos y producto de las transformaciones estatales y nacionales (caso yugoslavo o tchetcheno), se reproducen al nivel más microfísico de las comunidades andinas, donde la aculturación de los jóvenes varones provoca tensiones y conflictos con los adultos, pero también con el sector de mujeres, en el que así mismo la aculturación de algunas de ellas genera tensiones y conflictos aún más encarnizados dentro del mismo sector femenino, con los varones y los adultos. Así, mientras que en países occidentales mujeres musulmanas pueden reivindicar el derecho a llevar el velo, pero también a no llevarlo, en el medio indígena andino muchas mujeres reivindican el derecho a cambiar, reivindican un derecho a una identidad cultural opuesta a una supuesta "identidad étnica", a cambiar su vestimenta tradicional, mientras que otras entran en conflicto por reivindicar el no-cambio.

La concepción de lo local se complejiza aún más, cuando se tiene en cuenta en qué medida los diferentes flujos se articulan y relacionan entre ellos, convergen o compiten entre sí, se sobreponen, sobredeterminan e interpenetran, o se neutralizan recíprocamente. Siempre habrá que preguntarse cuál de los flujos se impone sobre los otros de manera más o menos estructural o coyuntural. Es evidente, por ejemplo, que en el caso de la Amazonía el escenario petrolero 
condiciona todos los otros escenarios. En otros casos la localización de los flujos puede resultar mucho más compleja. En el mencionado ejemplo de las mujeres indígenas el fenómeno de sus identidades étnicas o culturales entra en conflicto con sus identidades femeninas, y de hecho no son pocas las mujeres en dicha región, que escapan de sus comunidades y abdican de sus "relaciones de género" (de su identidad tan tradicional en el medio andino de ser madres y esposas), para en sus estrategias migratorias a las ciudades o a la costa dotarse de una nueva imagen de mujer.

Ahora bien, este proceso no hubiera sido posible sin un cambio en el fenómeno migracional: hasta ahora en el medio indígena (de la región estudiada) sólo migraban los varones, aunque la migración se volvía cada vez más precoz: mientras que, en la década de los 80 , la migración promedio concluía la fase de la adolescencia y actuaba casi como "rito de pasaje" a la edad adulta, en la actualidad la migración tiende a situarse en la transición de la infancia a la adolescencia. Pero ahora son ya las mujeres jóvenes que se convierten en el principal sector migrante. Obviamente, esta estrategia migratoria femenina de las mujeres indígenas, sin la cual éstas no hubieran buscado una nueva estrategia identitaria, ni

\section{Pero ahora son ya las mujeres jóvenes que se convierten en el principal sector migrante.}

tampoco hubieran protagonizado un conflicto cultural "intra-étnico", tal proceso migratorio ha sido posible por los cambios operados en los mercados laborales urbanos, y debido a una creciente oferta de empleos femeninos; mientras que las posibilidades de empleo para migrantes varones tiende a limitarse. Fenómeno este que no es ni diferente, ni ajeno del que se constata a escala más internacional o global, donde son también las mujeres las que encuentran una más amplia oferta laboral.

Cuando Castells diferencia los "espacios flujos" de los "espacios lugares", precisa que "un lugar es un espacio cuya forma, función y sentido componen un conjunto en el marco de una continuidad física" (p. 475). La idea de "continuidad física" es determinante, ya que nada distingue más y mejor la idea de lugar del concepto de local, que el diferente modelo de sociedad y de socialidad, en el que se inscriben ambas realidades. 
Mientras que el lugar se define por la contiguidad y la homogeneidad territorial de todos los fenómenos que tienen lugar en él, propio de las sociedades societales, cuya socialidad "mecánica" (no "orgánica" como la de las sociedades comunales) se funda en pertenencias, vínculos y contractualidades, lo local propio del modelo postsocietal de sociedad, "sociedad en redes", se define por la conectividad, por los contactos o conexiones, negociaciones o "alianzas estratégicas", todos ellos establecidos en espacios no-contiguos, sino discontinuos y distantes. De esta manera se pone de manifiesto la correspondencia entre dos categorías o enfoques, que definen conceptualmente lo local: por un lado en cuanto espacio de flujos y por otros lados la conectividad propia de una "network society"; puesto que es a través de redes y flujos que circulan y operan (recursos, personas, informaciones, fuerzas y poderes...). Si el actual modelo de sociedad responde a una "estructura en redes", dichas redes y sus interconexiones no sólo estructuran cada sociedad particular, sino también el conjunto de la sociedad global. Esto significa que la sociedad local funciona articulada en redes al interior de la sociedad regional, aquella y ésta se articulan a la sociedad nacional, y todas ellas se arti- culan en el sistema de redes inter - y trans - nacionales de la sociedad global. Mientras que la noción de "redes" hace referencia a la interconexión entre ámbitos, instituciones, sectores, grupos y personas, la idea de "flujos" se refiere más bien a las fuerzas e intereses e informaciones, que articulan cada sociedad y todas las sociedades entre sí.

Aunque de pasada, al definir el espacio lugar Castells los identifica como el espacio donde viven las personas. Sin embargo, ya en el mundo moderno, son muchas las personas, determinados grupos y sectores sociales, las clases dirigentes (ruling class) más globalizadas, que ya no viven en un lugar, sino que viven viajando, o bien desplazándose constantemente o bien habitando una multiresidencialidad; esta ubicuidad expresada en movilidades residenciales manifiesta cómo lo global se localiza de manera diferente: cuanto más globalizado es un grupo social menos vinculado a un lugar de residencia y más fácilmente localizable en cualquier lugar.

Sin embargo en el otro extremo de la sociedad existen también grupos marginales, sectores excluidos, expulsados de sus lugares habituales por la pobreza o las guerras, que tampoco viven en lugares, sino que habitan desplazados o formando parte de esas 
inmensas masas migratorias. Concebida en cuanto espacio de flujos, una sociedad local no presenta el mismo tipo de vínculo social, ni de tejido social, ni de socialidad, ni de relaciones sociales que los que caracterizan las sociedades concebidas como espacios de lugar, ya que los flujos, fuerzas, intereses e informaciones que se ejercen en el espacio local alteran profundamente el anterior modelo de sociedad. Por esta precisa razón lo local es la forma propia de una sociedad postsocietal, de una "sociedad en redes". En otras palabras hemos pasado de una "solidaridad orgánica", basada en las relaciones personales, a una "solidaridad mecánica" basada en la complementariedad de intereses y opciones racionales, para terminar en una sociedad glocal dominada por una solidaridad de carácter concurrencial y competitiva.

A partir de estos planteamientos teóricos es posible entender el desplazamiento que se opera desde los espacios rurales hacia los espacios locales urbanos, ya que la sociedad rural queda prácticamente disuelta y aniquilada bajo el paradigma de lo global y lo local: y por efecto de un nuevo modelo de sociedad, que des- truye todo el sistema de pertenencias, arraigos y adhesiones territoriales y familiares o comunales, los vínculos, las contractualidades las relaciones "face-to-face". Pensar lo local y tratar localmente una determinada sociedad, concebida como "espacio de flujos", no significa excluir completamente su dimensión de "espacio de lugares", sino únicamente considerar que las propiedades de lo local, a su vez enmarcadas en lo global, predominan sobre las características territoriales de una sociedad.

Según Castells "lo que distingue a la nueva estructura social, la sociedad en red, es que la mayoría de los procesos dominantes, que concentran poder, riqueza e información, se organizan en el espacio de los flujos. La mayor parte de la experiencia y el sentido humanos siguen teniendo una base local. La disyunción entre las dos lógicas espaciales es un mecanismo fundamental de dominio en nuestras sociedades, porque desplaza el núcleo de los procesos económicos, simbólicos y políticos del ámbito donde puede construirse sentido social y puede ejercerse control político"25. Según esto no hay hecho, fenómeno o institución social, que 
no deba ser repensado tanto en su dimensión glocal y como parte de una trama que atraviesa las distintas dimensiones espaciales (lo regional, nacional, internacional y mundial) cuanto en su dimensión de flujos y redes.

En las sociedades post-societales $y$ en el mundo globalizado los poderes, por ejemplo, ya no tienen lugar, pues no hay propiamente un lugar del poder: más aún toda topología del poder, cualquiera de sus ubicaciones, por muy visibles y simbólicas que aparezcan, no hacen más que encubrir la realidad de sus fuerzas, las cuales se distribuyen en redes, se interconectan, se dejan sentir por todo el tejido social y por todo el mundo, y se ejercen de manera tanto más ubicua y efectiva como invisible. Esta nueva morfología del poder, extraordinariamente poderosa para residir en un solo sitio, se ha capilarizado y entramado por toda la sociedad; es su capacidad de dilatación y de concentración, de metabolizarse en las fuerzas más microfísicas (las que van del voto ciudadano hasta la racionalidad burocrático administrativa) o en las instituciones más macrofísicas (desde las armas nucleares hasta las tecnologías más especializadas, pasando por la ciencia genética). Esta transformación de la realidad del poder y de la manera de concebirlo puede ser aplicada también a la economía, al mercado, al capital financiero; todos ellos reticulares, omnipresentes, fluyendo por el entramado glocal de todo el mundo.

En la sociedad local hay que considerar no tanto los hechos y las realidades, los grupos y las personas en sí mismos, cuanto la lógica de la red, la única capaz de canalizar las fuerzas y poderes desordenados de la complejidad y la interactividad. También la topología de la red obliga a pensar de manera diferente todos los hechos y realidades sociales, como por ejemplo el poder y la política. En la moderna sociedad glocal los poderes y las fuerzas globales y locales son de tal índole que han ido quedando en parte desinstitucionalizados y en mayor parte aún desterritorializados. Bajo la apariencia y el residuo de "estructuras" de poder, de "jerarquías" y "arquitécturas" políticas, hay que descubrir la nueva forma de redes y de tramas, de flujos y circuitos que adoptan los poderes y las fuerzas. La masa de tales fuerzas y poderes se ha hecho tan extraordinariamente superior a sus volúmenes, que se han vuelto $\mathrm{u}$ - tópicos, y por consiguiente ya ni se limitan ni se desgastan al quedar fijados a un lugar determinado; todo lo contrario es en la medida que circulan por la maya global y local, que se vuelven tan eficientes co- 
mo intangibles e invisibles. $\mathrm{Al}$ perder su verticalidad, al horizontalizarse, el poder -como el capital- gana en rapidez de acumulación y de cambio. Esta ubicuidad del poder es análoga a la del capital y a la de la información; y su eficacia nunca ha sido tan proporcional a su invisibilidad.

Esta comprensión de lo local, que propiamente se debería llamar glocal, afecta incluso al conocimiento: un modo de conocer basado en la experiencia inmediata, en la simple identificación, caracterización y clasifica- ción de los hechos, definido por la cuantificación de los fenómenos y por los datos estadísticos, nunca será capaz de comprender y explicar los procesos en su génesis y en sus causas, en las formas de actuar afectando las diferentes dimensiones espaciales e interactuando recíprocamente por todas ellas. No es casual que ante una complejización cada vez más densa del mundo glocal el pensamiento tiende a simplificarse. Este fenómeno no haría más que expresar un "mecanismo fundamental de dominación”. 